\title{
Analysis of Oligonucleotides by Electrospray Ionization Mass Spectrometry
}

Because of the high molecular weights and thermal lability of biomolecules such as nucleic acids and proteins, the analysis of these molecules by mass spectrometry is a rather difficult process. Two major problems in such analyses are the need for a "soft" ionization method capable of generating intact molecular ions and the limited upper mass range of most mass analyzers. In the mid 1980s, Fenn and co-workers demonstrated that electrospray ionization (ESI) could be used to analyze molecules with molecular weights $\left(M_{\mathrm{r}}\right)$ larger than the mass-to-charge ratio $(\mathrm{m} / \mathrm{z})$ limit of the mass analyzer (Fenn et al., 1989). Later work on oligonucleotides opened the door to accurate, high-resolution analysis of these compounds by ESI-MS (Covey et al., 1988).

ESI allows for the analysis of high-molecular-weight compounds through the generation of multiply charged ions in the gas phase. Because the basis of the mass spectrometric measurement is the $\mathrm{m} / \mathrm{z}$ value of the molecule, the presence of multiple charges on the molecule will result in a decrease in the $m / z$ values and allow characterization using mass analyzers with limited $\mathrm{m} / \mathrm{z}$ ranges. A typical example of the electrospray mass spectra one obtains for oligonucleotides is shown in Figure 10.2.1. The sample contains three unique

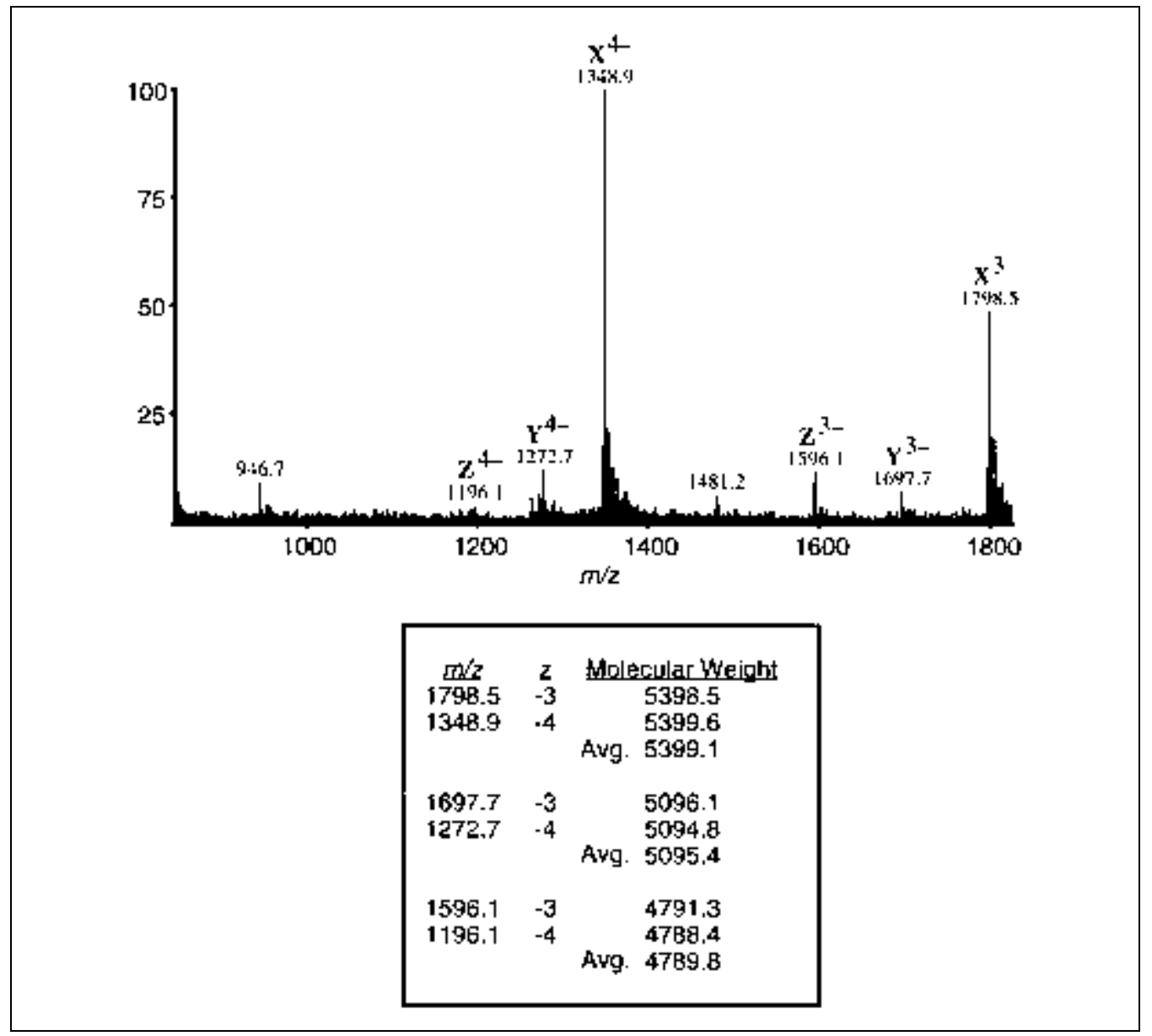

Figure 10.2.1 Representative electrospray mass spectrum of a mixture of oligonucleotides. $X=$ 17-mer, $Y=16-m e r$, and $Z=15-$ mer. The characteristic feature of an electrospray mass spectrum is the presence of multiply charged ions of each analyte. 


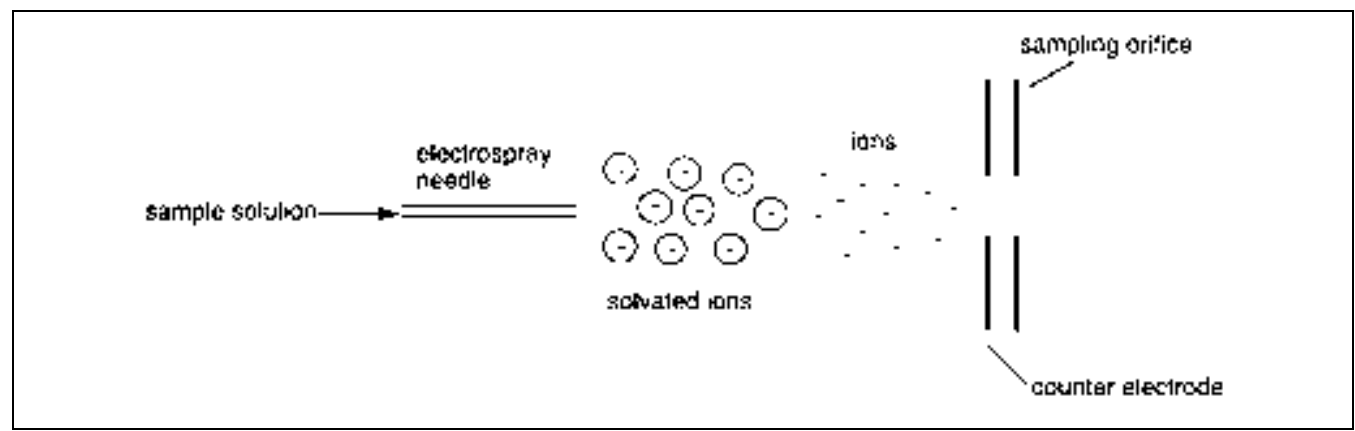

Figure 10.2.2 Diagram of a typical electrospray source.

oligonucleotides-a 17-mer, a 16-mer, and a 15-mer-designated X, Y, and Z, respectively. As is illustrated in this spectrum, each of the oligonucleotide species are detected as multiply charged negative ions. Thus, even though the molecular weights of each oligonucleotide are greater than the $\mathrm{m} / \mathrm{z}$ range of the mass analyzer (here 2000), the sample can still be identified due to the presence of the multiply charged peaks. A discussion on identification of oligonucleotide-ion charge state and molecular weight will be presented later in this unit.

A necessary requirement for ESI is that the analyte molecules be charged in solution. The negatively charged phosphate backbone of oligonucleotides allows for negative-ion-mode analysis of ESI-generated ions. A diagram of a typical electrospray source is shown in Figure 10.2.2. Transfer of ions from solution phase to the gas phase is accomplished by generating an electric field between a spraying needle that is held at a high negative potential and a counter-electrode held at ground or a positive potential some distance from the needle. The solution being sprayed exits the needle as a conical distribution of droplets ("Taylor cone"), each containing excess negative charge. A heated drying gas, such as nitrogen, is typically used to assist evaporation of the solvent sheath from the ion. The desolvated, multiply charged ion is then introduced into the mass spectrometer for analysis (Gaskell, 1997).

A number of applications of ESI to oligonucleotide and nucleic acid analysis have been reported since the introduction of this technique. Among the applications that will be discussed here are molecular mass measurement, sequence identification, and analysis of noncovalent complexes. In addition, the ESI source can be readily coupled with a number of separation techniques such as liquid chromatography (Apffel et al., 1997a,b; Glover et al., 1995), capillary electrophoresis (Barry et al., 1996), and capillary electrochromatography (Ding and Vouros, 1997) for the analysis of mixtures of oligonucleotides.

\section{ESI-MS VERSUS MALDI-MS FOR OLIGONUCLEOTIDE ANALYSIS}

Matrix-assisted laser desorption/ionization mass spectrometry (MALDI-MS) for oligonucleotide analysis is discussed in UNIT 10.1. Here, a brief comparison of the two approaches for oligonucleotide analysis is presented; a summary is provided in Table 10.2.1. The advantages of ESI-MS include higher mass accuracies, ease of coupling to on-line separation methods, and the ability to characterize noncovalent interactions; it is also the preferred method for gas-phase MS sequencing (tandem MS). MALDI-MS is more tolerant of sample contaminants, can handle complex mixture analysis, and is the

Analysis of Oligonucleotides by Electrospray Ionization Mass Spectrometry preferred method for sequencing by an exonuclease digestion protocol. In general, both methods are capable of providing molecular weight and sequence information from oligonucleotides, and the choice of ionization method depends on the available instrumentation, type of analyses desired, and user preference. 
Table 10.2.1 Summary of the Characteristics of MALDI-MS Versus ESI-MS

\begin{tabular}{lll}
\hline Parameter or characteristic & MALDI-MS & ESI-MS \\
\hline Mass errors & $1.0-0.05 \%$ & $0.1-0.005 \%$ \\
Upper mass limit & $\sim 36,000$ & $\sim 40,000$ \\
$\begin{array}{l}\text { Feasibility of: } \\
\quad \text { Mixture analysis }\end{array}$ & Yes & Difficult \\
$\quad \begin{array}{l}\text { Easy coupling to separation methods } \\
\text { Exonuclease sequencing }\end{array}$ & No & Yes \\
$\begin{array}{l}\text { Sequencing via gas-phase } \\
\text { dissociation (MS/MS) }\end{array}$ & Preferred & Possible \\
$\begin{array}{l}\text { Characterization of noncovalent } \\
\text { interactions }\end{array}$ & Possible & Preferred \\
\hline
\end{tabular}

\section{CONVENTIONAL VERSUS NANOELECTROSPRAY CONFIGURATION}

ESI is inherently a solution-based ionization technique. The sample solution flows through the charged ESI needle, resulting in the formation of the Taylor cone mentioned above. Currently, there are two different flow-rate/needle configurations utilized in ESI-MS: conventional electrospray, and micro- or nanoelectrospray. Conventional electrospray is performed using stainless steel needles (with 0.15 to 0.41 -mm-i.d. orifices) and the sample solution is delivered at a flow rate of 1 to $10 \mu \mathrm{L} / \mathrm{min}$. Many of the original ESI-MS oligonucleotide analysis results were obtained using this configuration.

Recently it has been shown that spraying capillaries with a 1 - to $2-\mu \mathrm{m}$-i.d. spraying orifice have several advantages over the traditional ESI needle, particularly in biomolecular analyses (Wilm and Mann, 1996). This "nanoelectrospray" source is essentially a capillary that has been pulled to a fine tip. The small spraying orifice requires low flow rates $(\mathrm{nL} / \mathrm{min})$, which aids in sample conservation. In addition, the overall efficiency of desolvation, ionization, and transfer is increased. The small size of the droplets generated means that one analyte molecule is present per droplet. Because the size of the droplets is significantly reduced, desolvation is easily achieved without the need of a drying gas. The overall charge-to-volume ratio of the droplets is also higher than in conventional ESI, which improves ionization. Transfer of ions into the mass analyzer is improved because the spraying tip can be placed close to the orifice of the analyzer ( 1 to $2 \mathrm{~mm}$ away). Another important advantage of the nanoelectrospray source is that it has a higher tolerance to salt adduction than conventional ESI. In addition, it can operate at high $\mathrm{pH}$. As described in the section on Sample Preparation, below, both of these characteristics can be useful in nucleic acid analysis.

\section{MASS ANALYZER CONFIGURATION}

ESI can be coupled with a large variety of mass analyzers. Table 10.2.2 lists the analyzers most often coupled to the ESI source. Commercial versions of these instruments are available for each of the different mass analyzers listed. Quadrupole mass analyzers are the most popular configuration due to their ease of operation and low cost. However, they suffer from poor resolution as well as a limited $\mathrm{m} / \mathrm{z}$ range $(\sim 3000)$. Triple-quadrupole instruments can be used to perform tandem MS experiments, and therefore are suitable when gas-phase sequencing experiments are of interest.

Two common mass analyzers that are useful for several types of analysis of oligonucleotides are the quadrupole ion-trap and the Fourier-transform ion-cyclotron resonance mass spectrometer (FTICR-MS; see Table 10.2.3 for definitions of the instrument configurations discussed in this unit). These instruments have an added advantage over

Purification and Analysis of Synthetic Nucleic Acids and Components 
Table 10.2.2 Mass Analyzers Typically Coupled to ESI Sources ${ }^{a}$

\begin{tabular}{|c|c|c|c|c|c|}
\hline Analyzer $^{b}$ & Resolution & Sensitivity & Mass accuracy & $\begin{array}{l}\text { Upper } m / z \\
\text { limit }\end{array}$ & $\begin{array}{c}\text { Tandem MS } \\
\text { capability }\end{array}$ \\
\hline TOF & Good & High & High & $\sim 40,000$ & No \\
\hline Quadrupole & Fair & Good & Fair & 3,000 & No \\
\hline Triple-quadrupole & Fair & High & Fair & 3,000 & Yes \\
\hline $\begin{array}{l}\text { Double-focusing } \\
\text { sector }\end{array}$ & High & Fair & High & 10,000 & Yes \\
\hline Ion-trap & Fair & Good & Fair & 3,000 & Yes \\
\hline FTICR & Very high & Good & Very high & 10,000 & Yes \\
\hline
\end{tabular}

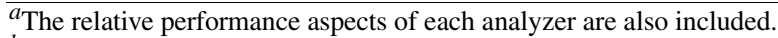

${ }^{b}$ See Table 10.2.3 for definitions of instrument configurations.

the other mass analyzers listed in Table 10.2.2 that they operate on the principle of ion trapping. With trapped-ion mass analyzers, the analyte ions are confined to a particular region of space and their subsequent analysis is performed as a function of time. In contrast, analysis of ions with quadrupole, triple-quadrupole, sector, and time-of-flight mass analyzers is performed by separating the analysis regions in space. Thus, trapped-ion instruments are ideal for performing multiple stages of tandem mass spectrometry because no additional hardware is needed (McLuckey and Habibi-Goudarzi, 1993; Little et al., 1994a; Habibi-Goudarzi and McLuckey, 1995; Little and McLafferty, 1995). Another advantage is that these instruments permit alternative dissociation schemes-be-

Table 10.2.3 Glossary of Mass Spectrometry Terms Used in This Unit

Collision-induced dissociation (CID)

Double-focusing mass spectrometer

Fourier-transform ion-cyclotron resonance mass spectrometer (FTICR-MS)

Ion-trap mass spectrometer

Quadrupole mass spectrometer

Tandem mass spectrometer (MS/MS)

Time-of-flight mass spectrometer (TOF-MS)

Triple-quadrupole mass spectrometer
Process in which an ion is dissociated as a result of interaction with a target neutral species

Mass spectrometer that uses direction and velocity to focus ions of the same mass and charge

Mass spectrometer in which ions are confined by an electric and magnetic field and detected on the basis of their cyclotron frequency at a particular excitation energy in the high magnetic field

Mass spectrometer in which ions can be confined for extended periods of time by the use of a quadrupolar electric field

Mass spectrometer in which ions with a desired $\mathrm{m} / \mathrm{z}$ are focused towards the detector by the use of a static and a high-frequency electric field Mass spectrometer in which ions of selected $\mathrm{m} / \mathrm{z}$ pass through two or more stages of analysis

Mass spectrometer which operates on the principle that ions of different $\mathrm{m} / \mathrm{z}$ with the same initial energy require different times to travel through a field-free region Mass spectrometer composed of three sets of quadrupole rods, the first and last set operated in a manner similar to the quadrupole mass spectrometer and the second (middle) set used as a collision cell to allow for MS/MS experiments 
sides the common collision-induced dissociation (CID) method - to be employed (Little et al., 1994b, 1996). Quadrupole ion-trap MS typically gives poorer resolution and mass accuracy than FTICR-MS. FTICR-MS offers the highest resolution and mass accuracy, but the instrumentation is not only more expensive, but also more difficult to operate.

Two additional mass analyzers can be used with ESI. A promising combination is the use of a time-of-flight (TOF) mass analyzer with an ESI source. At the time of writing, only first-generation ESI-TOF mass spectrometers are available and the ultimate effectiveness of the combination is not yet known. However, their high sensitivity, extended upper $\mathrm{m} / \mathrm{z}$ range, adequate resolution and mass accuracy, and high duty cycle suggests that ESI-TOF mass analyzers may soon replace quadrupole mass analyzers as the instruments of choice for molecular weight determinations using ESI-MS. Double-focusing sector instruments are suitable for use with electrospray sources, have high sensitivities and mass resolution, and have tandem MS capabilities. However, their complexity and the small number of vendor offerings has limited their use for oligonucleotide analysis by ESI-MS.

\section{SAMPLE PREPARATION}

The success of oligonucleotide analyses using ESI depends largely on sample preparation. When dealing with nucleic acids, the two key factors in sample preparation are reduction of cation adducts (oligonucleotide purification and desalting) and selection of a proper solvent system.

\section{Purification Methods}

The greatest difficulty in achieving accurate mass measurement of oligonucleotides and nucleic acids is the formation of cation adducts. The negative charge on the nucleic acid phosphate backbone results in a large degree of Coulombic strain. In solution, solvent molecules help reduce these Coulombic interactions. In the gas phase, where solvent molecules are absent, relief of the strain is achieved by neutralization or cation adduction. Figure 10.2.3 is a representative electrospray mass spectrum of an oligonucleotide with a large number of cation adducts. The presence of nonvolatile cation adducts such as sodium and potassium results in spectral peaks broadened by the adduction. In addition, the ion current is shared over a larger number of peaks, thereby decreasing sensitivity. As illustrated in Figure 10.2.3b, a number of cation-adduct combinations may be present for a particular charge state, and a complex mass spectrum results.

A number of purification techniques have been applied to nucleic acid samples (Stults and Marsters, 1991; Emmett and Caprioli, 1994; Little et al., 1994a; Potier et al., 1994; Greig and Griffey, 1995; Limbach et al., 1995; Liu et al., 1996, 1997; Muddiman et al., 1996a). Although these methods differ in protocol, the objective and end result are the same-to replace the nonvolatile (e.g., sodium and potassium) adducts with volatile ones. Most commonly, ammonium salts are exchanged for the nonvolatile adducts.

Purification techniques that reduce or eliminate the presence of cation adducts can be classified into two groups: off-line and on-line methods (Table 10.2.4). The former include ammonium acetate precipitation, dialysis, and HPLC purification. The latter include on-line microdialysis, on-line micro-HPLC, and solvent additives.

By far the most common purification method is ammonium acetate precipitation (see Basic Protocol 1; Stults and Marsters, 1991; Limbach et al., 1995). In this procedure, the oligonucleotide is mixed with ammonium acetate and the oligonucleotide in its ammonium salt form is precipitated from ethanol. This procedure can be repeated a number of times, and it is advisable to do so, as multiple precipitations increase the overall amount of salt exchange.

Purification and Analysis of Synthetic Nucleic Acids and Components

Current Protocols in Nucleic Acid Chemistry 


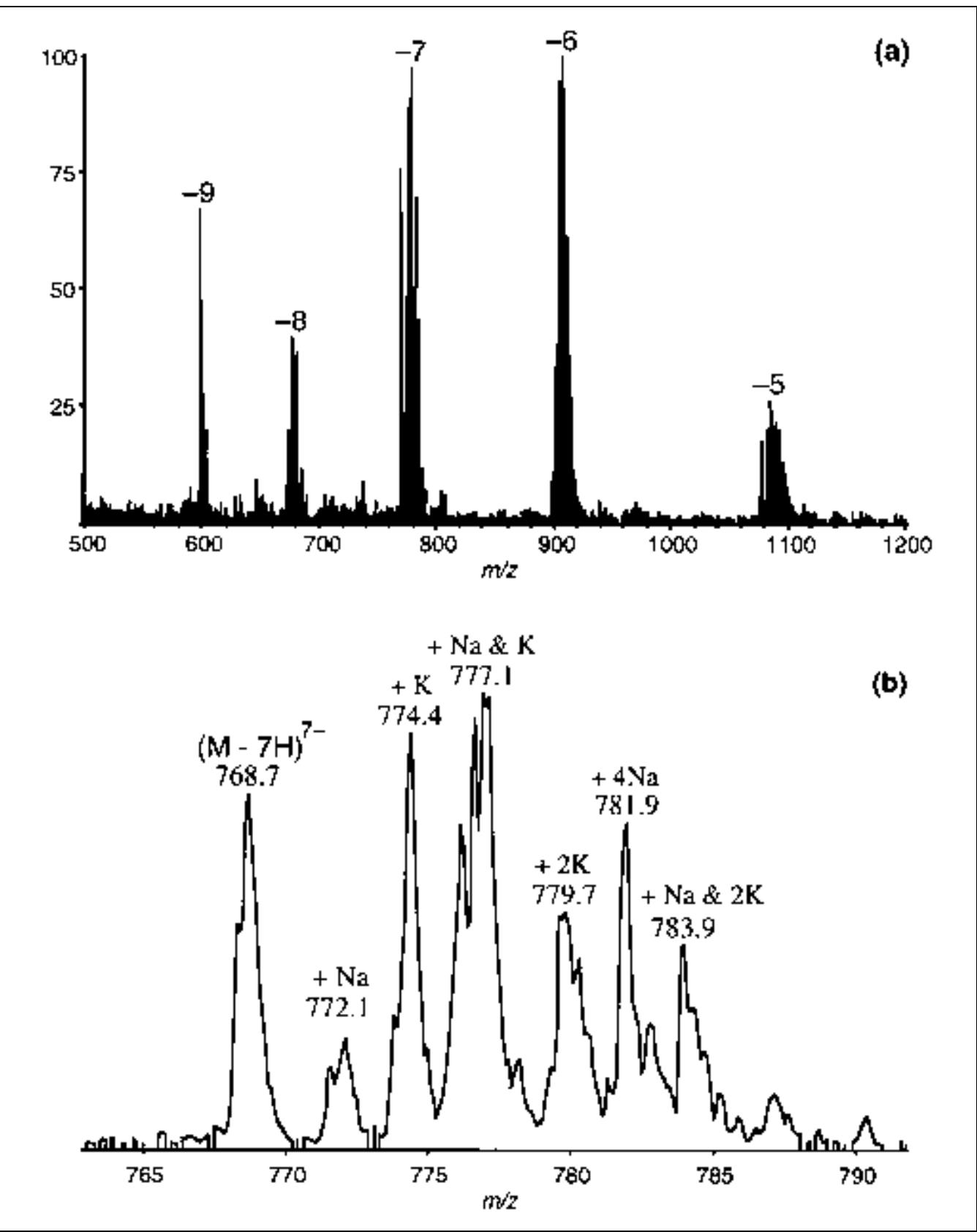

Figure 10.2.3 Representative electrospray mass spectrum used to illustrate the detrimental effects of cation adduction on mass spectral quality.

Analysis of Oligonucleotides by Electrospray Ionization Mass Spectrometry

Another routine approach to reducing salt adduct formation is to sequester the adducts using chelating agents and/or organic bases (see Basic Protocol 2; Potier et al., 1994; Greig and Griffey, 1995; Limbach et al., 1995; Muddiman et al., 1996a). The strategy here is to add chelating agents such as trans-1,2-diaminocyclohexane- $N, N, N^{\prime} N^{\prime}$-tetraacetic acid (CDTA; Limbach et al., 1995) or organic bases (Greig and Griffey, 1995; Muddiman et al., 1996a) such as triethylamine (TEA) that have a higher cation affinity than the nucleic acid. The cations will bind preferentially to these additives, leaving the nucleic acid in its free acid form. It is important to note that none of these purification techniques alone can remove all cation adducts, and using a combination of techniques-for example, ammonium acetate precipitation followed by CDTA and TEA addition-will improve results (Greig and Griffey, 1995; Limbach et al., 1995). 
Table 10.2.4 Techniques for Purifying Nucleic Acid Samples Prior to ESI-MS Analysis

\begin{tabular}{ll}
\hline Method & \multicolumn{1}{c}{ Reference } \\
\hline $\begin{array}{l}\text { Off line } \\
\text { Ammonium acetate precipitation }\end{array}$ & $\begin{array}{l}\text { Stults and Marsters (1991); Limbach et al. } \\
(1995)\end{array}$ \\
Reversed-phase HPLC & Little et al. (1994a) \\
Microdialysis & Liu et at. (1997) \\
On line & \\
Addition of co-matrix and/or chelating agent & $\begin{array}{l}\text { Potier et al. (1994); Greig and Griffey (1995); } \\
\text { Limbach et al. (1995) }\end{array}$ \\
Microdialysis & Liu et al. (1996) \\
Microscale liquid chromatography & Emmett and Caprioli (1994)
\end{tabular}

\section{Removal of Nonvolatile Cation Adducts from Oligonucleotide or Nucleic Acid Samples by Ammonium Acetate Precipitation}

The amount of salt adduction in nucleic acid samples can be reduced by exchanging the nonvolatile cations with the volatile ammonium cation (see section on Purification Methods, above). The effectiveness of the cation exchange increases with repetition of the precipitation procedure (Stults and Marsters, 1991; Limbach et al., 1995). This protocol should only be used for oligonucleotides larger than 25 bases - smaller oligonucleotides are difficult to precipitate and large sample losses will occur.

\section{Materials}

Oligonucleotide or nucleic acid sample, dry

$10 \mathrm{M}$ ammonium acetate

Absolute and $70 \%$ ethanol, ice cold

CAUTION: RNA samples are easily degraded by adventitious nucleases. If RNA is to be purified or analyzed, all laboratory equipment must be sterilized prior to use. Use of gloves is recommended during preparation of nucleic acid samples and solutions to avoid contamination of glassware and other equipment. Autoclaved distilled water and the highest available grade of salts must be used during solution preparation.

1. Dissolve the nucleic acid in 40 to $70 \mu \mathrm{L}$ ultrapure water to generate a 250 to $400 \mu \mathrm{M}$ solution.

2. Add $1 / 3$ volume of $10 \mathrm{M}$ ammonium acetate.

3. Add 2.5 vol ice-cold absolute ethanol to precipitate the nucleic acid. Store at least 3 hr at $-20^{\circ} \mathrm{C}$.

4. Centrifuge the suspension $15 \mathrm{~min}$ at $12,500 \mathrm{rpm}, 25^{\circ} \mathrm{C}$.

5. Decant the supernatant, working carefully to avoid disturbing the pellet.

6. Wash the pellet with $70 \%$ aqueous ethanol. Store the suspension at least $2 \mathrm{hr}$ at $-20^{\circ} \mathrm{C}$.

7. Centrifuge the suspension $15 \mathrm{~min}$ at $12,500 \mathrm{rpm}$.

8. Decant the supernatant and lyophilize the pellet.

9. Dissolve the pellet in ultrapure water to a final concentration of 300 to $1000 \mu \mathrm{M}$.

Purification and Analysis of Synthetic Nucleic Acids and Components 


\section{Removal of Nonvolatile Cation Adducts from Oligonucleotide or Nucleic Acid Samples with Chelating Agents and/or Organic Bases and ESI-MS Sample Preparation}

This protocol describes the steps for preparing oligonucleotide and nucleic acid solutions for analysis by ESI-MS. The addition of chelating agents or organic bases serves to sequester cations, thereby reducing the extent to which adducts are observed in the mass spectra (see section on Purification Methods, above). Each of these agents will reduce the amount of adduct formation, but the results are usually better when both materials are used. This protocol is the recommended choice for analyzing small oligonucleotides $(\leq 25$ bases). For larger oligonucleotides, this procedure should be used in conjunction with ammonium acetate precipitation (see Basic Protocol 1).

\section{Materials}

Oligonucleotide or nucleic acid sample

trans-1,2-Diaminocyclohexane- $N, N, N^{\prime}, N^{\prime}$-tetraacetic acid (CDTA)

Ethylenediaminetetraacetic acid (EDTA)

$0.1 \%$ aqueous triethylamine

Appropriate solvent: $30 \%$ to $70 \%$ aqueous acetonitrile, isopropanol, or methanol (see section on Solvent Selection, below, for discussion of how to choose an appropriate solvent.)

CAUTION: RNA samples are easily degraded by adventitious nucleases. If RNA is to be purified or analyzed, all laboratory equipment must be sterilized prior to use. Use of gloves is recommended during preparation of nucleic acid samples and solutions to avoid contamination of glassware and other equipment. Autoclaved distilled water and the highest available grade of salts must be used during solution preparation.

1. For oligonucleotides $>25$ bases, carry out ammonium acetate precipitation (see Basic Protocol 1).

2. Prepare a 1 to $10 \mu \mathrm{M}$ solution of oligonucleotide in the appropriate organic solvent.

3. Add $5 \mu \mathrm{L}$ of $0.1 \%$ triethylamine to each $100 \mu \mathrm{L}$ of oligonucleotide solution.

4. If analyzing intact nucleic acids, add CDTA or EDTA to the sample so as to obtain a final CDTA or EDTA molar concentration three times that of the nucleic acid sample.

5. This solution is now ready for immediate analysis by ESI-MS.

\section{Solvent Selection}

A second aspect of sample preparation is the selection of an appropriate solvent for electrospray. Two important criteria are (1) that the solvent readily evaporate to facilitate the transfer of the ion from the liquid to the gas phase, and (2) that the solvent allow the generation of a large number of ions. It has been shown that as the organic composition of the solvent increases, the signal intensity increases as well (Bleicher and Bayer, 1994). In that particular study, the best ion signals were seen with acetonitrile, although other solvents such as isopropanol or methanol have been used. Typically, the aqueous oligonucleotide solution is mixed in a 1:1 ratio with the organic solvent. This allows the oligonucleotide to remain solubilized while assisting the ESI process by improving evaporation.

Analysis of Oligonucleotides by Electrospray Ionization Mass Spectrometry
The second consideration in solvent selection is that the solvent must allow the ready formation of ions. The main factor in this case is solution $\mathrm{pH}$ : as $\mathrm{pH}$ increases, more negative ions are produced and the signal intensity rises (Bleicher and Bayer, 1994). This 
increase in $\mathrm{pH}$ can be achieved by adding an organic base such as TEA to the nucleic acid solution, which also reduces cation adduction, as previously discussed. Finally, the $\mathrm{pH}$ can be manipulated to change the charge-state distribution of the peaks observed in the spectra (Stults and Marsters, 1991; Cheng et al., 1995; Griffey et al., 1997). As the pH increases, the charge-state distribution shifts to higher charge states or lower $\mathrm{m} / \mathrm{z}$. Thus, when using a mass analyzer with a limited $\mathrm{m} / \mathrm{z}$ range, it is preferable to work at high solution $\mathrm{pH}$.

The typical procedure for preparing samples for ESI-MS analysis is as follows. After purification of the oligonucleotide or nucleic acid sample by one of the off-line techniques mentioned above, the oligonucleotide sample is dissolved in ultrapure (e.g., Nanopure) water to a stock concentration of 50 to $100 \mu \mathrm{M}$. An aliquot of the stock solution is then diluted into the organic solvent of interest to a final concentration of 1 to $10 \mu \mathrm{M}$. Chelating agents or organic bases such as TEA can be added to this solution prior to analysis.

The deciding criteria for final concentration and organic content of solvent depend on the particular type of information desired from the mass spectrometric step. When the molecular weight or sequence of single-stranded oligonucleotides or intact nucleic acids are to be determined, the percentage organic solvent should be between $50 \%$ and 90\%; smaller oligonucleotides are more soluble at the higher percentages of organic solvent. The best concentration will vary by instrument. When noncovalent interactions of double-stranded oligonucleotides or intact nucleic acids are to be investigated, the organic content should remain as low as possible while still generating a stable electrospray (typically $10 \%$ to $35 \%$ ). Analyte concentrations in these cases are typically higher $(\sim 25 \mu \mathrm{M})$.

\section{MOLECULAR WEIGHT DETERMINATION USING ESI-MS}

Molecular weight determination of oligonucleotides and intact nucleic acids is one of the more common applications of ESI, as well as one of the simplest. This approach can be used to verify the expected base composition of an oligonucleotide by comparing the measured mass to the mass corresponding to the predicted composition. The analysis of small oligonucleotides $(<10,000 \mathrm{Da})$ has become routine. In fact, if constraints can be placed on the number of A, C, G, or U/T residues allowed in the molecule, then the base composition of an oligonucleotide up to the 14-mer level can be determined unambiguously by accurate mass measurement alone (Pomerantz et al., 1993). For larger oligonucleotides and nucleic acids, however, extremely high mass accuracies are required to confirm base composition assignments.

The most impressive molecular weight measurements have been obtained using FTICRMS (Chen et al., 1995; Cheng et al., 1996a). With this high-resolution mass analyzer, DNA molecules in the 110-MDa range have been detected with a $10 \%$ uncertainty in the molecular weight value (Chen et al., 1995). Other relatively large oligonucleotides and nucleic acids in the molecular weight region between 15,000 and 40,000 Da have also been analyzed. Among the applications of ESI-MS to these molecules are the analysis of intact tRNA and rRNA (Limbach et al., 1995) and PCR products (Naito et al., 1995; Muddiman et al., 1996b, 1997). In these cases, the errors in mass measurement are typically $\sim 0.01 \%$ or less.

Because ESI produces multiply charged ions, the resulting spectra may be complicated by the presence of several ions of the same mass but different charge and their respective cation adducts. Determination of the charge state of a particular peak may be accomplished using mathematical equations. For a negatively charged peak, $\mathrm{p}_{1}$, one may write Equation 10.2.1:

Purification and Analysis of Synthetic Nucleic Acids and Components

Current Protocols in Nucleic Acid Chemistry 


$$
p_{1} z_{1}=M_{\mathrm{r}}-M_{\mathrm{a}} z_{1}=M_{\mathrm{r}}-1.0079 z_{1}
$$

\section{Equation 10.2.1}

where $p_{1}$ is the $m / z$ value of the peak, $z_{1}$ is the charge of the peak, $M_{\mathrm{r}}$ is the molecular weight of the sample, and $M_{\mathrm{a}}$ is the molecular weight of the charge-carrying species. Typically, the charge-carrying species is a proton; therefore, $M_{\mathrm{a}}=1.0079$. Similarly, for a second peak, $\mathrm{p}_{2}$, that is $j$ peaks away from $\mathrm{p}_{1}$, one may write Equation 10.2.2:

$$
p_{2}\left(z_{1}-j\right)=M_{\mathrm{r}}-M_{\mathrm{a}}\left(z_{1}-j\right)=M_{\mathrm{r}}-1.0079\left(z_{1}-j\right)
$$

\section{Equation 10.2.2}

Solving Equations 10.2.1 and 10.2.2, Equation 10.2.3 is obtained for $z_{1}$ :

$$
z_{1}=-j\left(p_{2}+1.0079\right) /\left|p_{1}-p_{2}\right|
$$

\section{Equation 10.2.3}

Once the charge state is known, Equation 10.2.1 can be used to determine the molecular weight of the sample being analyzed. The data in Figure 10.2.1 will serve to illustrate how charge-state and molecular weight determinations are made. To determine the charge state, for example, of the peak at 1348.9, the following values can be substituted into Equation 10.2.3: $p_{1}=1348.9, p_{2}=1798.5$, and $j=1$. By substituting these values into Equation 10.2.3, a value of $z_{1}$ of -4 is obtained for the charge state. Using Equation 10.2.1, $M_{\mathrm{r}}$ is found to be 5399.6. To obtain a more accurate value for $M_{\mathrm{r}}$, it should be calculated from the values measured for a number of adjacent peaks and the calculated values then averaged, as shown in Figure 10.2.1. The value one obtains from solving Equation 10.2.3 should be an integer; if it is not, a different pair of $m / z$ values should be chosen. For example, if one chooses $p_{1}=1348.9, p_{2}=1697.7$, and $j=1$, a value of $z_{1}=-4.87$ is obtained for the charge state. Because this value is not an integer, one can conclude that the $\mathrm{m} / \mathrm{z}$ values of 1348.9 and 1697.7 do not compose an oligonucleotide of the same mass.

In some cases, multiple peaks are not present in the electrospray series or are difficult to discern (such as in tandem MS experiments), and some other means of determining the charge state of the ion is necessary. On a high-resolution instrument such as a sector or FTICR mass spectrometer, the ability to resolve isotope peaks is helpful in determining the charge state of a particular peak. If the spacing between a peak A and its consecutive isotope peak $\mathrm{A}+1$ is 1 (e.g., for ${ }^{13} \mathrm{C}$ ), then this peak will correspond to the singly charged species. If, for example, the difference between the A and A+1 peaks detected in the mass spectrum is $0.20 \mathrm{u}$, then the A peak corresponds to the species carrying a -5 charge (i.e., $1 / 5=0.20 \mathrm{u}$ ). In general, if the difference between the A and A+1 peaks is $1 / x \mathrm{u}$, the $\mathrm{A}$ peak will correspond to the $-x$ charge state.

Low-resolution instruments typically cannot resolve ${ }^{13} \mathrm{C}$ isotopes for multiply charged peaks where $z>3$. Often, the charge state of the particular ion can be determined by the mass shift of a cation adduct. For example, a single sodium adduct will appear at an $\mathrm{m} / \mathrm{z}$ value $22 \mathrm{u}$ higher than the unadducted $\mathrm{m} / \mathrm{z}$ value for singly charged ions, ${ }^{22} / 2=11 \mathrm{u}$ higher for doubly charged ions, ${ }^{22} / 3=7.3 \mathrm{u}$ higher for triply charged ions, and so forth (see Fig. 10.2.3b).

Analysis of Oligonucleotides by Electrospray Ionization Mass Spectrometry

\section{OLIGONUCLEOTIDE AND NUCLEIC ACID SEQUENCING USING ESI-MS}

A powerful application of ESI-MS in the analysis of oligonucleotides and nucleic acids is sequence determination. The two most common techniques for sequencing are tandem MS and indirect sequencing using enzyme digestions (Limbach, 1996). In tandem MS, 
A

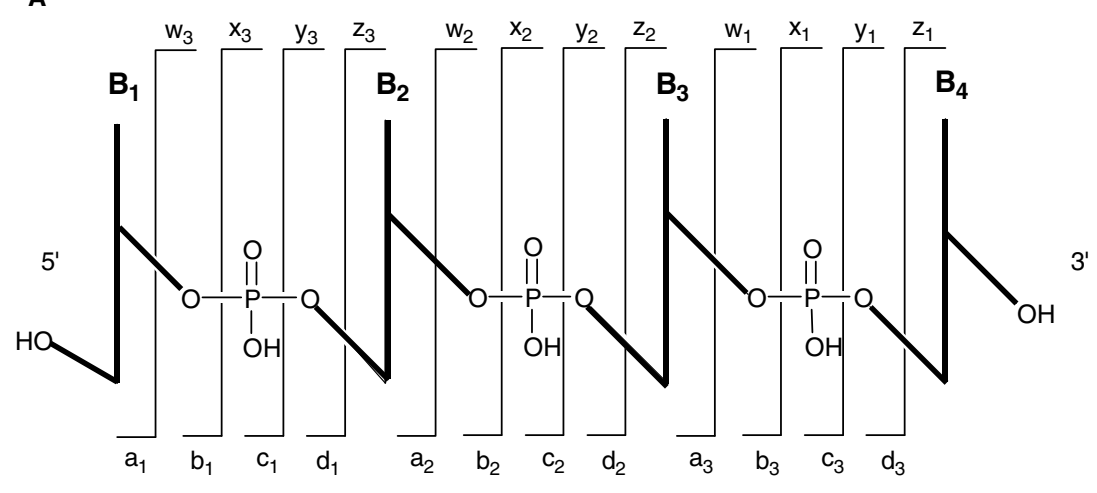

B
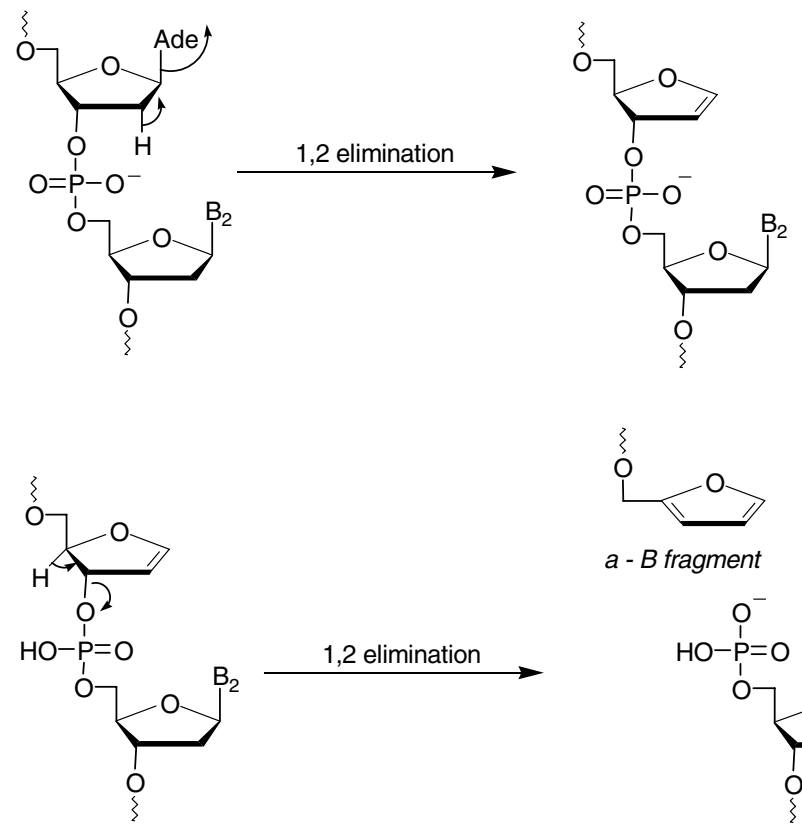

a - B fragment

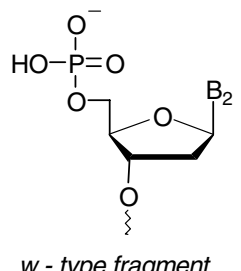

Figure 10.2.4 (a) Nomenclature for the dissociation products of oligonucleotides. (b) Prevalent oligonucleotide fragmentation mechanism, especially with ion-trap and FTICR-MS instruments (McLuckey and Habibi-Goudarzi, 1993). The mechanism involves two elimination reactions, the first resulting in loss of the base and the second resulting in cleavage at the sugar to yield (a-B)-type and w-type fragments.

molecules are allowed to dissociate in the gas phase, and analysis of the resulting fragmentation pattern yields insight into the structure and, in the case of oligonucleotides, sequence of the molecule. Figure 10.2.4a gives the nomenclature for assigning dissociation products of oligonucleotides. As can be seen in the figure, a large number of fragmentation pathways are possible. This large number of pathways results in highly complicated spectra, and as oligonucleotide length increases, so does the spectral complexity. Figure 10.2.4b shows the most common fragmentation pathway oligonucleotides are found to follow during tandem MS experiments. Generally, the resulting mass spectrum will be composed primarily of a-B fragments and the w-type fragments, although the other dissociation products may also be present (McLuckey and HabibiGoudarzi, 1993). Tandem MS analysis of oligonucleotides using ESI have been carried out using triple-quadrupole (Barry et al., 1995, 1996; Wolter and Engels, 1995; Boschenok

Purification and Analysis of Synthetic Nucleic Acids and Components 
and Sheil, 1996; Ni et al., 1996a), ion-trap (McLuckey et al., 1992, 1995; McLuckey and Habibi-Goudarzi, 1993; Habibi-Goudarzi and McLuckey, 1995), and FTICR mass analyzers (Little and McLafferty, 1995; Little et al., 1995, 1996).

Although the techniques and the information generated by each of these mass analyzers are similar, there do exist substantial differences, primarily in the preferred order of base loss. For instance, in ion-trap and FTICR-MS studies, adenine is usually lost, and this leads to cleavage of the $3^{\prime} \mathrm{C}-\mathrm{O}$ bond of the sugar, generating w-type and (a-B)-type fragments (Fig. 10.2.4; McLuckey et al., 1992). In contrast, triple-quadrupole studies show no preference for loss of any one base over another (Barry et al., 1995; Boschenok and Sheil, 1996; Ni et al., 1996a).

Recently, McCloskey and co-workers (Ni et al., 1996b) developed an algorithm for the sequence identification of oligonucleotides using a triple-quadrupole mass spectrometer equipped with an ESI source. The algorithm is based on the analysis of relative ion abundances and charge-state distributions of ions generated using low-energy collisionally induced dissociation (CID). In their preliminary study, the sequence of an "unknown" 15-mer was determined. In a subsequent study, the algorithm was employed to determine the sequence of oligonucleotides in combinatorial libraries composed of mixtures of 8-mers or 12-mers containing two and three unknown nucleotides in the sequence, respectively (Pomerantz et al., 1997). The greatest advantage presented by this technique for this application is the ability to sequence isomeric oligonucleotides. When analyzing mixtures using tandem MS, components of a mixture are analyzed by selecting (one at a time) each molecular ion in the mass spectrum. Once isolated, it is allowed to undergo CID, and the fragment-ion spectrum is analyzed to determine the sequence. If, however, the molecular ion selected in the primary mass spectrum represents two or more components of equal mass, the CID spectrum becomes more difficult to interpret. By employing the sequencing algorithm, the isomeric oligonucleotides can be distinguished and sequenced.

The algorithm is not without its limitations, however. In the case of isomeric mixtures, as the number of components represented by the molecular ion in the primary mass spectrum increases, it becomes nearly impossible to determine the individual oligonucleotides unambiguously without a previous fractionation step. The task becomes even more difficult if the number of components in the mixture is unknown. In addition, as one of the factors used for sequence determination is relative ion abundance, the analysis of minor components becomes difficult in a mixture where one or more components are in a molar excess.

Table 10.2.5 Characteristic Mass Losses During Exonuclease Digestion for Naturally Occurring Deoxynucleotides (dX) and Ribonucleotides $(\mathrm{rX})^{a}$

\begin{tabular}{lccc}
\hline Nucleotide & $\begin{array}{c}\Delta \text { mass (singly } \\
\text { charged) }\end{array}$ & $\begin{array}{c}\Delta \text { mass (doubly } \\
\text { charged) }\end{array}$ & $\Delta$ mass (triply charged) \\
\hline $\mathrm{dA}$ & 313.27 & 156.64 & 104.42 \\
$\mathrm{dG}$ & 329.27 & 164.64 & 109.76 \\
$\mathrm{dC}$ & 289.25 & 144.63 & 96.417 \\
$\mathrm{dT}$ & 304.26 & 152.13 & 101.42 \\
$\mathrm{rA}$ & 329.27 & 164.64 & 109.76 \\
$\mathrm{rG}$ & 345.27 & 172.64 & 115.09 \\
$\mathrm{rC}$ & 305.25 & 152.62 & 101.75 \\
$\mathrm{ru}$ & 306.26 & 153.13 & 102.09
\end{tabular}

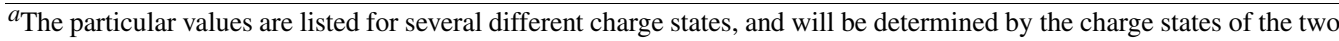
oligonucleotides used to find $\Delta$ mass. All values are atomic weight based. 
Apart from these specific drawbacks in analyzing mixtures, it is uncertain whether the algorithm will be applicable when other mass analyzers or high-energy CID are employed. Nonetheless, its development represents a large step forward in the simplification of tandem MS analyses of oligonucleotides. Although it is questionable whether this technique will be applicable to larger molecules, it can clearly be used to analyze oligonucleotides up to the 15-mer range. In addition, the sequence location as well as the nature (i.e., sugar or base) of modifications can be determined.

The second approach for sequencing using ESI-MS involves the partial enzymatic digestion of oligonucleotides or nucleic acids followed by mass-spectral analysis of the digestion products (see Basic Protocol 3). Enzymatic digestion may consist of either exonuclease or endonuclease digestion. Sequence identification using exonuclease digestion is a relatively straightforward, simple method, particularly for smaller oligonucleotides (Limbach et al., 1994; Glover et al., 1995). Exonuclease digestions generate consecutive backbone cleavages which, when analyzed using mass spectrometry, create a "mass ladder." The sequence of the molecule is then determined from the mass difference between adjacent peaks in the spectrum. Table 10.2.5 lists the expected mass difference for loss of each of the deoxy- and ribonucleotides. $5^{\prime}$ and $3^{\prime}$ exonucleases can be used to generate $5^{\prime}$ and $3^{\prime}$ sequence information, respectively. Modified nucleosides can be easily identified with this method from the anomalous mass shifts caused by the modifications.

\section{Oligonucleotide or Nucleic Acid Sequencing Using Sequential Exonuclease Digestion and ESI-MS}

This protocol describes the procedure for on-line sequencing of oligonucleotides or nucleic acids using ESI-MS. To generate $3^{\prime}$ sequence information, phosphodiesterase I should be used, as it cleaves oligonucleotides in the $3^{\prime}$-to- $5^{\prime}$ direction. Similarly, if $5^{\prime}$ sequence information is required, phosphodiesterase II should be used. During the first few minutes of analysis, information can be gathered on the first five or so nucleotides in the sequence. After longer reaction times, sequence information can be obtained for nucleotides further along the chain (Limbach et al., 1994). This protocol is most effective for oligonucleotides $<30$-mers.

\section{Materials}

Oligonucleotide or nucleic acid sample, dry

Phosphodiesterase I (from snake venom, SVP; Sigma) or phosphodiesterase II

(from calf spleen, CSP; Sigma or Worthington) dissolved to $0.1 \mathrm{U} / \mu \mathrm{L}$ in water

5.0 M ammonium acetate (APPENDIX 2A), $\mathrm{pH} 9.8$ to 10.4 for phosphodiesterase I $o r$

6 to 7 for phosphodiesterase II

Organic solvent (see section on Solvent Selection, above)

Variable-flow-rate syringe pump

1. Mix $\sim 1.2 \mathrm{nmol}$ dry oligonucleotide, $10 \mu \mathrm{L}(1.0 \mathrm{U})$ phosphodiesterase, and $0.5 \mathrm{M}$ ammonium acetate at the appropriate $\mathrm{pH}$ to adjust the $\mathrm{pH}$ for optimum enzyme digestion.

2. Dilute the solution in an appropriate percentage of organic solvent to a concentration of $10 \mathrm{pmol} / \mu \mathrm{L}$.

3. Draw the digestion mixture into a syringe and infuse the mixture into the ESI-MS at a flow rate of $\sim 2 \mu \mathrm{L} / \mathrm{min}$ using a syringe pump.
BASIC

PROTOCOL 3

Purification and Analysis of Synthetic Nucleic Acids and Components 
Digestion will occur in the syringe as the data is acquired. Data can be acquired continuously or every 2 min until digestion is complete.

4. The syringe may be cooled (to $0^{\circ} \mathrm{C}$ to $10^{\circ} \mathrm{C}$ ) or heated (to $30^{\circ} \mathrm{C}$ to $45^{\circ} \mathrm{C}$ ) in a water bath in order to decrease or increase digestion times, respectively.

Although direct analysis of the digestion mixtures can be advantageous because the sequence information is obtained from a difference in mass rather than an absolute value, it is sometimes preferable to separate the digestion products before MS analysis (Glover et al., 1995). For example, one may wish to separate digestion products when dealing with oligonucleotides $\geq 30$-mers, since the large number of peaks generated can decrease sensitivity.

\section{Analysis of RNA Modifications Using Endonuclease Digestion and ESI-MS}

For larger nucleic acids, the generation of smaller fragments using endonucleases facilitates sequence assignments. One of the more significant advances in this area has been achieved by McCloskey and co-workers. This group has developed a protocol based on site-specific endonuclease digestions to determine modifications in transfer RNA (tRNA) and ribosomal RNA (rRNA; Crain, 1990; Bruenger et al., 1993; Kowalak et al., 1993, 1994, 1995, 1996). The steps involved in this sequencing method are outlined in Figure 10.2.5, and the enzymatic digestions used in this method are outlined in the protocols below. The purified RNA sample is divided in two. One of the samples is digested with nuclease $\mathrm{P} 1$ and alkaline phosphatase to generate its component nucleosides (see Basic Protocol 4). Liquid chromatography mass spectrometry (LC-MS) is then used to characterize the nucleosides present in the mixture, as well as to determine if any modifications are present (evidenced by a difference in mass from the "naturally" occurring nucleosides;

Analysis of Oligonucleotides by Electrospray Ionization Mass Spectrometry

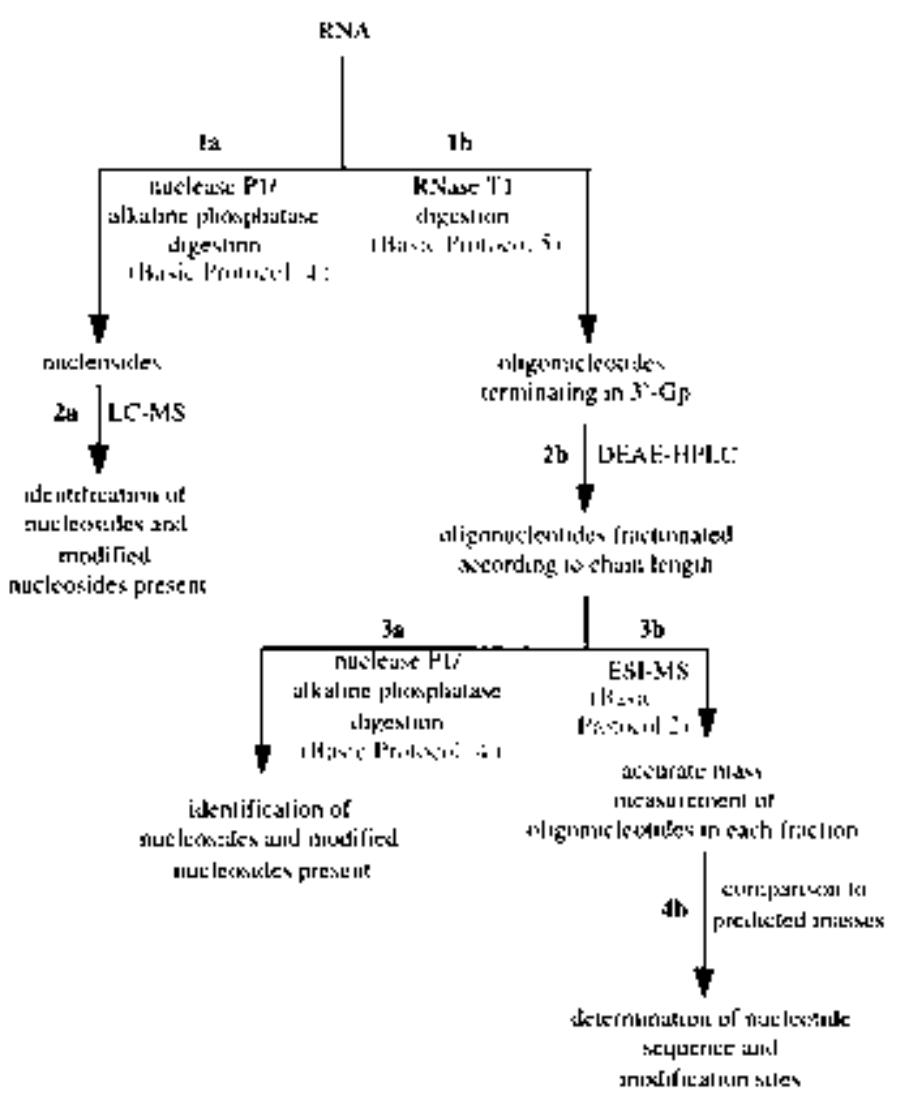

Figure 10.2.5 Endonuclease-based RNA sequencing protocol. 
step 1a). The other RNA sample is subjected to RNase T1 digestion (see Basic Protocol 5) to generate oligonucleotide fragments terminating in a $3^{\prime}-\mathrm{Gp}$ (step 1b). The resulting oligonucleotides are then separated based on their chain length using DEAE-HPLC (step $2 b$ ). Each of the collected fractions (which typically contain more than one oligonucleotide) is then separated into two batches. One set is subjected to nuclease P1 and alkaline phosphatase digestion as in step $1 \mathrm{a}$ and the nucleosides and modified nucleosides present in each fraction are determined (step 3a). Each oligonucleotide fraction in the second set is analyzed using ESI-MS (step 3b). The accurate mass measurement obtained is then compared to the predicted masses from the known gene sequence from which the nucleotide sequence, as well as sites of modifications, can be determined (step 4b).

Because the number of RNase T1 fragments that are generated can be quite large, an alternative procedure is to isolate regions of interest selectively by hybridizing complementary oligodeoxynucleotides to the region and using mung bean nuclease to digest the unhybridized sections of RNA (Kowalak et al., 1995). The purified oligoribonucleotides remaining may then be subjected to the protocol detailed in Figure 10.2.5.

\section{Total Nucleoside Digestion of RNA}

The following procedure can be used to digest RNA to its component nucleosides. This is a necessary step in the determination of post-transcriptional modifications using the method developed by McCloskey and co-workers. The amounts of enzyme specified are those required to completely digest $\sim 20 \mu \mathrm{g}\left(0.5 A_{260}\right.$ units) of RNA (Crain, 1990).

\section{Materials}

RNA sample, dry

Nuclease P1 (Sigma), dissolved to $2 \mathrm{U} / \mu \mathrm{L}$ in $0.05 \mathrm{M}$ ammonium acetate, $\mathrm{pH} 5.3$

Snake venom phosphodiesterase I (SVP) or bovine intestinal phosphodiesterase (both from Sigma; the former is preferred), dissolved to $0.001 \mathrm{U} / \mu \mathrm{L}$ in water Bacterial alkaline phosphatase (Sigma), suspended in $2.5 \mathrm{M}$ ammonium sulfate $1 \mathrm{mM}$ Tris.Cl, $\mathrm{pH} 7.4$ (APPENDIX 2A)

$0.1 \mathrm{M}$ ammonium acetate, $\mathrm{pH} 5.3$

$1 \mathrm{M}$ ammonium bicarbonate, $\mathrm{pH} 7.8$

$37^{\circ}$ to $100^{\circ} \mathrm{C}$ water bath

CAUTION: RNA samples are easily degraded by adventitious nucleases. If RNA is to be purified or analyzed, all laboratory equipment must be sterilized prior to use. Use of gloves is recommended during preparation of nucleic acid samples and solutions to avoid contamination of glassware and other equipment. Autoclaved distilled water and the highest available grade of salts must be used during solution preparation.

1. Dissolve the RNA sample in $1 \mathrm{mM}$ Tris. $\mathrm{Cl}, \mathrm{pH} 7.4$, to a concentration of 1 to $3 \mu \mathrm{g} / \mu \mathrm{L}$.

2. Heat the solution $3 \mathrm{~min}$ at $100^{\circ} \mathrm{C}$ to denature the nucleic acid, and immediately chill on ice.

3. Add $1 / 10$ vol of $0.1 \mathrm{M}$ ammonium acetate, $\mathrm{pH}$ 5.3.

4. Add $2 \mathrm{U}$ nuclease $\mathrm{P} 1$ and incubate the solution $2 \mathrm{hr}$ at $45^{\circ} \mathrm{C}$.

If thiolated nucleosides are present, include $1 / 10$ vol of $1 \mathrm{mM}$ dithiothreitol in the buffer to reduce sulfur loss.

Purification and Analysis of Synthetic Nucleic Acids and Components 
5. Add $1 / 10$ vol of $1 \mathrm{M}$ ammonium bicarbonate, $\mathrm{pH} 7.8$, and $0.002 \mathrm{U}$ phosphodiesterase $\mathrm{I}$, and incubate $2 \mathrm{hr}$ at $37^{\circ} \mathrm{C}$.

The $\mathrm{pH}$ of ammonium bicarbonate will increase with time, so the $\mathrm{pH}$ of this buffer should be checked, and adjusted if necessary by addition of acetic acid, prior to use.

6. Add $0.5 \mathrm{U}$ alkaline phosphatase and incubate $1 \mathrm{hr}$ at $37^{\circ} \mathrm{C}$.

Bacterial alkaline phosphatase from Sigma is provided as a suspension in $2.5 \mathrm{M}$ ammonium sulfate. The ammonium sulfate does not typically interfere with subsequent LC/MS analysis. If dry alkaline phosphatase is used, dissolve the enzyme to $0.5 \mathrm{U} / \mu \mathrm{L}$ in $2.5 \mathrm{M}$ ammonium sulfate.

7. The solution is ready for immediate analysis by LC/MS.

For details of LC-MS analysis of RNA, consult Pomerantz and McCloskey (1990).

The digest can be stored at $-20^{\circ} \mathrm{C}$ before use; in this case it must first be neutralized with acetic acid.

BASIC

PROTOCOL 5
Analysis of Oligonucleotides by Electrospray Ionization Mass Spectrometry

\section{RNase T1 Digestion of RNA}

Total nucleoside digestion of RNA will yield information on the kinds of post-transcriptional modifications present in RNA, but analysis of RNase T1 products is required to identify the sequence location of these modifications. The following is the procedure for generating RNase T1 fragments of RNA (Kowalak et al., 1993).

\section{Materials}

RNA sample, dry

RNase T1 (Sigma or Ambion), suspended in $3.2 \mathrm{M}$ ammonium sulfate, $\mathrm{pH} \sim 6$

$1 \mathrm{mM}$ EDTA/50 mM Tris.Cl, pH 7.5 (see APPENDIX 2A for preparation of EDTA and Tris. $\mathrm{Cl}$ stock solutions)

$37^{\circ} \mathrm{C}$ water bath

CAUTION: RNA samples are easily degraded by adventitious nucleases. If RNA is to be purified or analyzed, all laboratory equipment must be sterilized prior to use. Use of gloves is recommended during preparation of nucleic acid samples and solutions to avoid contamination of glassware and other equipment. Autoclaved distilled water and the highest available grade of salts must be used during solution preparation.

1. Dissolve $8 \mathrm{nmol}$ RNA in $1 \mathrm{mM}$ EDTA/50 $\mathrm{mM}$ Tris $\mathrm{Cl}, \mathrm{pH} 7.5$, to a concentration of $0.2 \mathrm{nmol} / \mu \mathrm{L}$.

2. Heat the solution $3 \mathrm{~min}$ at $100^{\circ} \mathrm{C}$ to denature the nucleic acid, and immediately chill on ice.

3. Add $2000 \mathrm{U}$ RNase $\mathrm{T} 1$ and incubate $30 \mathrm{~min}$ at $37^{\circ} \mathrm{C}$.

RNase $T 1$ from Sigma is supplied as a suspension in $3.2 \mathrm{M}$ ammonium sulfate. The ammonium sulfate does not typically interfere with subsequent HPLC analysis. If dry RNase Tl is to be used, dissolve the enzyme to $1000 \mathrm{U} / \mu \mathrm{L}$ in $3.2 \mathrm{M}$ ammonium sulfate.

4. The solution is ready for immediate analysis by HPLC.

For details of HPLC analysis of RNA, consult Kowalak et al., 1993.

The digest can be stored at $-20^{\circ} \mathrm{C}$ prior to HPLC, although long-term storage ( $>6$ months) is not recommended as it may lead to RNA degradation. 
Among the advantages of ESI in nucleic acid analysis is that this is what is termed a "soft" ionization technique in the sense that the ionization process itself does not cause molecular fragmentation. There are several classes of noncovalent complexes that can be studied using ESI-MS (Przybylski and Glocker, 1996; Loo, 1997). Among these are specific complex stoichiometry, competition of complex components, specificity of solution conditions for complex formation, and gas-phase stability of complex ions. Each of these properties can be studied by varying certain ESI parameters. For example, studies on complex stoichiometry can be achieved by changing solution concentrations, ESI temperature, and ESI voltage. Competitions between components in a complex can be studied by inducing modifications in the components and monitoring the changes effected on the ESI spectra. Solution requirements are determined by changing such variables as buffer $\mathrm{pH}$. Lastly, the gas-phase stability of the complexes may be determined using CID experiments (Przybylski and Glocker, 1996). In addition, ESI-MS has several advantages over the other techniques traditionally used to study noncovalent complexes (e.g., NMR, $\mathrm{X}$-ray crystallography), including the ability to accurately measure molecular mass and the smaller amounts of sample required.

The earliest studies of nucleic acid complexes were carried out on oligonucleotide duplexes. Typically, the observation of oligonucleotide duplexes is achieved with samples dissolved in $10 \mathrm{M}$ ammonium acetate. The duplex is usually observed at low charge states (high $\mathrm{m} / \mathrm{z}$ ), requiring the use of an analyzer with an extended mass range. Besides small oligonucleotide duplexes, double-stranded PCR products have also been observed (Wunschel et al., 1996). The complexes studied consisted of 100 to $105 \mathrm{bp}$. However, accurate mass measurement of such large complexes is difficult to obtain even on a high-resolution instrument because of the large amount of cation adduction present in these samples. Quadruplex structures of DNA have also been observed using ESI-MS (Goodlett et al., 1993). However, formation of these complexes requires the presence of high concentrations of monatomic cations (e.g., $\mathrm{Na}^{+}$) which, as previously discussed, degrade spectral quality.

In addition to base-paired nucleic acid hybridizations, ESI-MS has also been used to analyze the binding of proteins to DNA and RNA. Among the studies that have been conducted on protein-nucleic acid complexes are determination of gas-phase stability (Gale and Smith, 1995), recognition studies (Sannes-Lowery et al., 1997), measurement of dissociation constants (Greig et al., 1995), determination of binding stoichiometry (Cheng et al., 1996b) and specificity (Gao et al., 1995), and competitive binding studies (Cheng et al., 1996c).

ESI-MS for the study of noncovalent complexes is still a developing technique. Apart from the fundamental studies of noncovalent complexes, this methodology may have more far-reaching applications. Among the proposed applications (Przybylski and Glocker, 1996) are sequence determination by hybridization, analysis of antisense oligonucleotide complexes, and analysis of intercalation complexes.

\section{SUMMARY}

The speed and sensitivity of mass spectrometric analyses make this technique an attractive approach to analyzing oligonucleotides and nucleic acids. With the advent of "soft" ionization techniques such as MALDI and ESI, the analysis of these molecules in their intact form has brought mass spectrometry into the forefront as a viable method for characterization of nucleic acids. Although MALDI has a greater tolerance for salt adducts than ESI, the latter technique has the advantage that the generation of multiply charged ions allows the analysis of these molecules using more routine analyzers such as

Purification and Analysis of Synthetic Nucleic Acids and Components 
quadrupoles that may have a limited $m / z$ range. In addition, ESI-MS allows the analysis of intact noncovalent complexes. This characteristic permits the study of these complexes in the gas-phase with minimal sample amounts, and provides complementary information to the classic solution phase methods.

\section{LITERATURE CITED}

Apffel, A., Chakel, J.A., Fischer, S., Lichtenwalter, K., and Hancock, W.S. 1997a. Analysis of oligonucleotides by HPLC-electrospray ionization mass spectrometry. Anal. Chem. 69:1320-1325.

Apffel, A., Chakel, J.A., Fischer, S., Lichtenwalter, K., and Hancock, W.S. 1997b. New procedure for the use of high-performance liquid chromatography-electrospray ionization mass spectrometry for the analysis of nucleotides and oligonucleotides. J. Chromatogr. A 777:3-21.

Barry, J.P., Vouros, P., Schepdael, A.V., and Law, S.-J. 1995. Mass and sequence verification of modified oligonucleotides using electrospray tandem mass spectrometry. J. Mass Spectrom. 30:993-1006.

Barry, J.P., Muth, J., Law, S.-J., Karger, B.L., and Vouros, P. 1996. Analysis of modified oligonucleotides by capillary electrophoresis in a polyvinylpyrrolidone matrix coupled with electrospray mass spectrometry. J. Chromatogr. A 732:159-166.

Bleicher, K. and Bayer, E. 1994. Various factors influencing the signal intensity of oligonucleotides in electrospray mass spectrometry. Biol. Mass Spectrom. 23:320-322.

Boschenok, J. and Sheil, M.M. 1996. Electrospray tandem mass spectrometry of nucleotides. Rapid Commun. Mass Spectrom. 10:144149.

Bruenger, E., Kowalak, J.A., Kuchino, Y., McCloskey, J.A., Mizushima, H., Stetter, K.O., and Crain, P.F. 1993. 5S rRNA modification in the hyperthermophilic archaea Sulfolobus solfataricus and Pyrodictium occultum. FASEB J. 7:196-200.

Chen, R., Cheng, X., Mitchell, D.W., Hofstadler, S.A., Wu, Q., Rockwood, A.L., Sherman, M.G., and Smith, R.D. 1995. Trapping, detection, and mass determination of coliphage T4 DNA ions of $10^{8}$ Da by electrospray ionization Fourier transform ion cyclotron resonance mass spectrometry. Anal. Chem. 34:1159-1163.

Cheng, X., Gale, D.C., Udseth, H.R., and Smith, R.D. 1995. Charge state reduction of oligonucleotide negative ions from electrospray ionization. Anal. Chem. 67:586-593.

Cheng, X., Camp, D.C., II, Wu, Q., Bakhtiar, R., Springer, D.L., Morris, B.J., Bruce, J.E., Anderson, G.A., Edmonds, C.G., and Smith, R.D. 1996a. Molecular weight determination of plasmid DNA using electrospray ionization mass spectrometry. Nucl. Acids Res. 24:2183-2189.

Cheng, X., Harms, A.C., Goudreau, P.N., Terwilliger, T.C., and Smith, R.D. 1996b. Direct measurement of oligonucleotide binding stoichiometry of gene $\mathrm{V}$ protein by mass spectrometry. Proc. Natl. Acad. Sci. U.S.A. 93:7022-7027.

Cheng, X., Morin, P.E., Harms, A.C., Bruce, J.E., Ben-David, Y., and Smith, R.D. 1996c. Mass spectrometric characterization of sequence-specific complexes of DNA and transcription factor PU.1 DNA binding domain. Anal. Biochem. 239:35-40.

Covey, T.R., Bonner, R.F., Shushan, B.I., and Henion, J. 1988. The determination of protein, oligonucleotide, and peptide molecular weights by ion-spray mass spectrometry. Rapid Commun. Mass Spectrom. 2:249-256.

Crain, P.F. 1990. Preparation and enzymatic hydrolysis of DNA and RNA for mass spectrometry. Methods Enzymol. 193:782-790.

Ding, J. and Vouros, P. 1997. Capillary electrochromatography and capillary electrochromatography—mass spectrometry for the analysis of DNA adduct mixtures. Anal. Chem. 69:379-384.

Emmett, M.R. and Caprioli, R.M. 1994. Micro-electrospray mass spectrometry: Ultra-high sensitivity analysis of peptides and proteins. J. Am. Soc. Mass Spectrom. 5:605-613.

Fenn, J.B., Mann, M., Meng, C.K., Wong, S.F., and Whitehouse, C.M. 1989. Electrospray ionization for mass spectrometry of large biomolecules. Science 246:64-71.

Gale, D.C. and Smith, R.D. 1995. Characterization of noncovalent complexes formed between minor groove binding molecules and duplex DNA by electrospray ionization-mass spectrometry. J. Am. Soc. Mass Spectrom. 6:1154-1164.

Analysis of Oligonucleotides by Electrospray Ionization Mass Spectrometry

Gao, Q., Cheng, X., Smith, R.D., Yang, C.F., and Goldberg, I.H. 1996. Binding specificity of post-activated neocarzinostatin chromophore drug-bulged DNA complex studied using electrospray ionization mass spectrometry. J. Mass Spectrom. 31:31-36.

Gaskell, S.J. 1997. Electrospray: Principles and practice. J. Mass Spectrom. 32:677-688. 
Glover, R.P., Sweetman, G.M.A., Farmer, P.B., and Roberts, G.C.K. 1995. Sequencing of oligonucleotides using high performance liquid chromatography and electrospray mass spectrometry. Rapid Commun. Mass Spectrom. 9:897-901.

Goodlett, D.R., Camp, D.G., II, Hardin, C.C., Corregan, M., and Smith, R.D. 1993. Direct observation of a DNA quadruplex by electrospray ionization mass spectrometry. Biol. Mass Spectrom. 22:181-183.

Greig, M. and Griffey, R.H. 1995. Utility of organic bases for improved electrospray mass spectrometry of oligonucleotides. Rapid Commun. Mass Spectrom. 9:97-102.

Greig, M.J., Gaus, H., Cummins, L.L., Sasmor, H., and Griffey, R.H. 1995. Measurement of macromolecular binding using electrospray mass spectrometry. Determination of dissociation constants for oligonucleotide-serum albumin. J. Am. Chem. Soc. 117:831-832.

Griffey, R.H., Sasmor, H., and Greig, M.J. 1997. Oligonucleotide charge states in negative ionization electrospray-mass spectrometry are a function of solution ammonium ion concentration. J. Am. Soc. Mass Spectrom. 8:155-160.

Habibi-Goudarzi, S. and McLuckey, S.A. 1995. Ion trap collisional activation of the deprotonated deoxymononucleoside and deoxydinucleoside monophosphates. J. Am. Soc. Mass Spectrom. 6:102-113.

Kowalak, J.A., Pomerantz, S.C., Crain, P.F., and McCloskey, J.A. 1993. A novel method for the determination of posttranscriptional modification in RNA by mass spectrometry. Nucl. Acids Res. 21:4577-4585.

Kowalak, J.A., Dalluge, J.J., McCloskey, J.A., and Stetter, K.O. 1994. Role of posttranscriptional modification in stabilization of transfer RNA from hyperthermophiles. Biochemistry 33:7869-7876.

Kowalak, J.A., Bruenger, E.B., and McCloskey, J.A. 1995. Posttranscriptional modification of the central loop of domain V in E. coli 23S ribosomal RNA. J. Biol. Chem. 270:17758-17764.

Kowalak, J.A., Bruenger, E., Hashizume, T., Peltier, J.M., Ofengand, J., and McCloskey, J.A. 1996. Structural characterization of $\mathrm{U}^{*}$-1915 in domain IV from Escherichia coli 23S ribosomal RNA as 3-methylpseudouridine. Nucl. Acids Res. 24:688-693.

Limbach, P.A. 1996. Indirect mass spectrometric methods for characterizing and sequencing oligonucleotides. Mass Spectrom. Rev. 15:297-336.

Limbach, P.A., Crain, P.F., and McCloskey, J.A. 1994. Enzymatic sequencing of oligonucleotides with electrospray mass spectrometry. Nucl. Acids Res. Symp. Ser. 31:127-128.

Limbach, P.A., Crain, P.F., and McCloskey, J.A. 1995. Molecular mass measurement of intact ribonucleic acids via electrospray ionization quadrupole mass spectrometry. J. Am. Soc. Mass Spectrom. 6:27-39.

Little, D.P. and McLafferty, F.W. 1995. Sequencing 50-mer DNAs using electrospray tandem mass spectrometry and complementary fragmentation methods. J. Am. Chem. Soc. 117:6783-6784.

Little, D.P., Chorush, R.A., Spier, J.P., Senko, M.W., Kelleher, N.L., and McLafferty, F.W. 1994a. Rapid sequencing of oligonucleotides by high-resolution mass spectrometry. J. Am. Chem. Soc. 116:4893-4897.

Little, D.P., Speir, J.P., Senko, M.W., O’Conner, P.B., and McLafferty, F.W. 1994b. Infrared multiphoton dissociation of large multiply charged ions for biomolecule sequencing. Anal. Chem. 66:2809-2815.

Little, D.P., Thannhauser, T.W., and McLafferty, F.W. 1995. Verification of 50- to 100-mer DNA and RNA sequences with high-resolution mass spectrometry. Proc. Natl. Acad. Sci. U.S.A. 92:2318-2322.

Little, D.P., Aaserud, D.J., Valaskovic, G.A., and McLafferty, F.W. 1996. Sequence information from 42-108-mer DNAs (complete for a 50-mer) by tandem mass spectrometry. J. Am. Chem. Soc. 118:93529359.

Liu, C., Muddiman, D.C., Tang, K., and Smith, R.D. 1997. Improving the microdialysis procedure for electrospray ionization mass spectrometry of biological samples. J. Mass Spectrom. 32:425-431.

Liu, C., Wu, Q., Harms, A.C., and Smith, R.D. 1996. On-line microdialysis sample cleanup for electrospray ionization mass spectrometry of nucleic acid samples. Anal. Chem. 68:3295-3299.

Loo, J.A. 1997. Studying non-covalent protein complexes by electrospray ionization mass spectrometry. Mass Spectrom. Rev. 16:1-23.

McLuckey, S.A. and Habibi-Goudarzi, S. 1993. Decompositions of multiply charged oligonucleotide anions. $J$. Am. Chem. Soc. 115:12085-12095.

McLuckey, S.A., Van Berkel, G.J., and Glish, G.L. 1992. Tandem mass spectrometry of small, multiply charged oligonucleotides. J. Am. Soc. Mass Spectrom. 3:60-70.

McLuckey, S.A., Viadyanathan, G., and Habibi-Goudarzi, S. 1995. Charged vs. neutral nucleobase loss from multiply charged oligonucleotide anions. J. Mass Spectrom. 30:1222-1229.

Muddiman, D.C., Cheng, X., Udseth, H.R., and Smith, R.D. 1996a. Charge state reduction with improved signal intensity of oligonucleotides in electrospray ionization mass spectrometry. J. Am. Soc. Mass Spectrom. 7:697-706.

Purification and Analysis of Synthetic Nucleic Acids and Components 
Muddiman, D.C., Wunschel, D.S., Liu, C., Pasa-Tolic, L., Fox, K.F., Fox, A., Anderson, G.A., and Smith, R.D. 1996b. Characterization of PCR products from Bacilli using electrospray ionization FTICR mass spectrometry. Anal. Chem. 68:3705-3712.

Muddiman, D.C., Anderson, G.A., Hofstadler, S.A., and Smith, R.D. 1997. Length and base composition of PCR-amplified nucleic acids using mass measurements from electrospray ionization mass spectrometry. Anal. Chem. 69:1543-1549.

Naito, Y., Ishikawa, K., Koga, Y., Tsuneyoshi, T., Terunuma, H., and Arakawa, R. 1995. Molecular mass measurement of polymerase chain reaction products amplified from human blood DNA by electrospray ionization mass spectrometry. Rapid Commun. Mass Spectrom. 9:1484-1486.

Ni, J., Pomerantz, S.C., and McCloskey, J.A. 1996a. Rapid sequencing of modified oligonucleotides using tandem mass spectrometry with electrospray ionization. Nucl. Acids Symp. Ser. 35:113-114.

Ni, J., Pomerantz, S.C., Rozenski, J., Zhang, Y., and McCloskey, J.A. 1996b. Interpretation of oligonucleotide mass spectra for determination of sequence using electrospray ionization and tandem mass spectrometry. Anal. Chem. 68:1989-1999.

Pomerantz, S.C. and McCloskey, J.A. 1990. Analysis of RNA hydrolysates by liquid chromatography-mass spectrometry. Methods Enzymol. 193:796-824.

Pomerantz, S.C., Kowalak, J.A., and McCloskey, J.A. 1993. Determination of oligonucleotide composition from mass spectrometrically measured molecular weight. J. Am. Soc. Mass Spectrom. 4:204-209.

Pomerantz, S.C., McCloskey, J.A., Tarasow, T.M., and Eaton, B.E. 1997. Deconvolution of combinatorial oligonucleotide libraries by electrospray ionization tandem mass spectrometry. J. Am. Chem. Soc. 119:3861-3867.

Potier, N., Dorsselaer, A.V., Cordier, Y., Roch, O., and Bischoff, R. 1994. Negative electrospray ionization mass spectrometry of synthetic and chemically modified oligonucleotides. Nucl. Acids Res. 22:3895-3903.

Przybylski, M. and Glocker, M.O. 1996. Electrospray mass spectrometry of biomacromolecular complexes with noncovalent interactions-new analytical perspectives for supramolecular chemistry and molecular recognition processes. Angew. Chem. Intl. Ed. Engl. 35:806-826.

Sannes-Lowery, K.A., Mack, D.P., Hu, P., Mei, H.-Y., and Loo, J.A. 1997. Positive ion electrospray ionization mass spectrometry of oligonucleotides. J. Am. Soc. Mass Spectrom. 8:90-95.

Stults, J.T. and Marsters, J.C. 1991. Improved electrospray ionization of synthetic oligodeoxynucleotides. Rapid Commun. Mass Spectrom. 5:359-363.

Wilm, M. and Mann, M. 1996. Analytical properties of the nanoelectrospray ion source. Anal. Chem. 68:1-8.

Wolter, M.A. and Engels, J.W. 1995. Nanoelectrospray mass spectrometry/mass spectrometry for the analysis of modified oligoribonucleotides. Eur. Mass Spectrom. 1:583-590.

Wunschel, D.S., Fox, K.F., Fox, A., Bruce, J.E., Muddiman, D.C., and Smith, R.D. 1996. Analysis of double-stranded polymerase chain reaction products from the Bacillus cereus group by electrospray ionization Fourier transform ion cyclotron resonance mass spectrometry. Rapid Commun. Mass Spectrom. 10:29-35.

Contributed by Lenore M. Polo and Patrick A. Limbach

Louisiana State University

Baton Rouge, Louisiana

Analysis of 